\title{
Gövde analizi çalışmalarında yeni ve kombine bir yöntem
}

A new and combined method in stem analysis studies

\author{
Abbas ŞAHİN ${ }^{1}$ \\ Gafura AYLAK ÖZDEMIR ${ }^{2}$ \\ Emrah ÖZDEMIR ${ }^{2}$
}

${ }^{1}$ Marmara Ormanc1lık Araștırma Enstitüsü Müdürlüğü, İstanbul

2 İstanbul Üniversitesi-Cerrahpaşa, Orman Fakültesi, İstanbul

Sorumlu yazar (Corresponding author) Abbas ŞAHİN

abbassahin@yahoo.com

Geliş tarihi (Received)

06.09.2021

Kabul Tarihi (Accepted)

10.09.2021

Sorumlu editör (Corresponding editor)

Murat BAŞAR

muratbasar@ogm.gov.tr

Atıf (To cite this article): Sahin, A., Aylak Özdemir, G., Özdemir, E. (2021). Gövde analizi çalışmalarında yeni ve kombine bir yöntem. Ormancıllk Araştırma Dergisi, 8 (2) , 208-210. DOI 10.17568/ogmoad. 990904

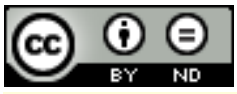

Creative Commons Atıf Creative Consons Atr Türetilemez 4.0 Uluslarara
Lisansı ile lisanslanmıștır.

\section{Sayın Editör,}

Hasılat çalışmalarında artım ve büyüme ilişkilerini ortaya koymak için kullanılan ve en sağlıklı sonuçların elde edildiği yöntemlerden birisi de gövde analizi yöntemidir. Gövde analizi çalışmalarının materyalini, dikili ağaçların kesilmesinden elde edilen kesitler üzerinden alınan ölçümler oluşturmaktadır. Yakın zamana kadar ülkemizde yapılan gövde analizi çalışmaları, kesitler üzerinde manuel olarak yapılan ölçümlerden yararlanarak gerçekleştirilmiştir. Gövde analizi çalışmalarında kullanılan verileri; kesitteki halka sayısı, çift kabuk kalınlığı ve genel olarak ta 5 ya da 10 yillık periyodlar halinde halka genişliklerine ait saptanmış değerler oluşturmuştur. Uygulanan bu klasik yöntem, oldukça zaman almakta, çok fazla ölçüm hatasına neden olmakta ve her yıllık halkanın hassas bir şekilde ölçülmesini zorlaştırmaktadır. Ayrıca ölçülen verilerin bilgisayara aktarılması da oldukça zaman almakta ve bunun dışında veri girişi hatalarına da neden olmaktadır.

$\mathrm{Bu}$ yöntem yerine, bilgisayar tekniklerinin ve yazılımlarının kullanılarak kesitteki yıllık halka sayılarını ve genişliklerini çok daha hassas bir şekilde belirleyen WinDENDRO programından da (URL1) yararlanarak, hasılat çalışmalarının istediği sonuçları elde edebilecek kombine bir yöntem geliştirilmiştir. WinDENDRO programı kullanılarak elde edilen gövde analiz verileri, MS Office Excel programına aktarıldıktan sonra, Şahin (2020) tarafından geliştirilen eklenti yazılım ile düzenlenerek, Özdemir ve Özdemir (2016) tarafından, MS Excel 2010 programının VBA özelliğinden yararlanılarak geliştirilen gövde analiz programına (GOAP) aktarılarak analiz çalışmaları gerçekleştirilmektedir. Tüm bu çalışmaların sonucunda ise tek ağaca ilişkin hacim, artım ve büyüme ilişkileri belirlenmektedir. Belirtilen yöntem üç aşamadan oluşan bir kombine yöntem olup ayrıntıları aşağıda verilmiştir. Bunlar;

Birinci aşamada; kesitler zımparalanıp yüksek çözünürlüklü Epson LA2400 Scanner ile tarandıktan sonra yıllık halka sayımı, halka genişlikleri ile kabuk kalınlıklarını ölçme işlemi WinDENDRO yazılımı ile gerçekleştirilmektedir. Bilgisayar yazılımı, üretilen veriyi metin belgesi (.txt) olarak kaydetmektedir. Gövde analizi gerçekleştirilen tüm kesitler ya da artım kalemleri için; metin belgesinin (.txt), yanı sıra görüntü (.tif) ve grafik verilerde üretilmektedir (Şekil 1). Analiz sonucunda elde edilen veriler yıl esaslı değerlendirilecek nitelikte üretildiğinden, tek ağaçlara ilişkin çıktılar her yıla ait elde edilebilece- 


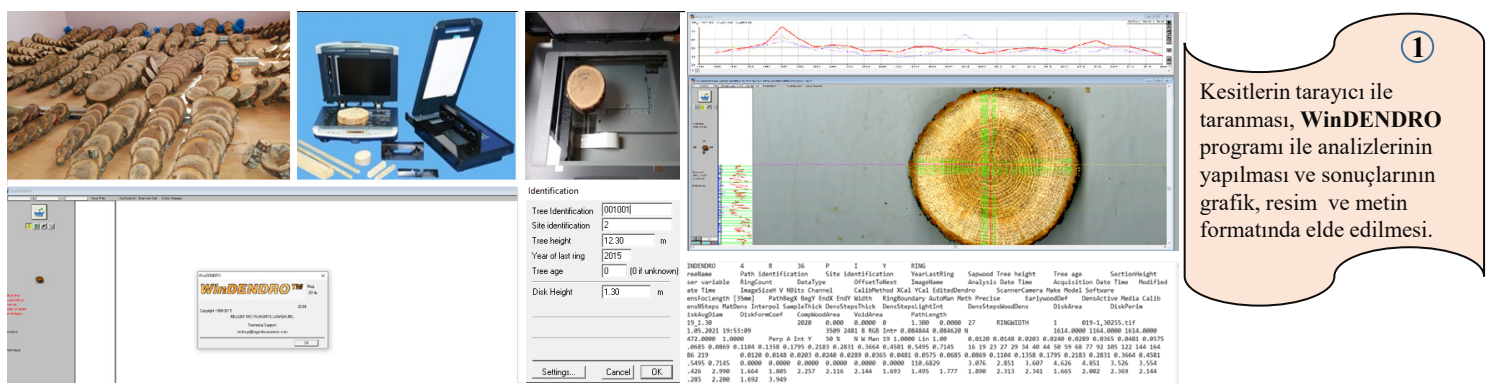

Şekil 1. Kesitlerin taranıp bilgisayara aktarılarak gövde analiz işlemlerinin yapılması

ği gibi aynı zamanda yaş periyotları halinde de elde edilebilmektedir.

İkinci aşamada; WinDENDRO programının kullanılmasıyla elde edilen metin belgesi (.txt) formatındaki gövde analiz verileri, MS Office Excel programına aktarılmaktadır. Üretilen veriler, ağaç gövdesi hacim ve hacim elemanlarını verecek şekilde, ağaç kesitinin elde edildiği yıl yani son halkanın hangi yıla ait olduğu, kesitteki halka sayısı, kesitlerin kaç yönlü ölçüldüğü dikkate alınacak şekilde Şahin (2020) tarafından MS Excel 2016 prog- ramının VBA makro özelliğinden yararlanarak tasarlanmış eklenti yazılımıyla düzenlenmektedir. Veriler düzenlendikten sonra, bu kısmın ikinci aşamasında ise; ağaç yaşı, ilk kesit yüksekliği, seksiyon uzunluğu gibi parametreler, oluşturulmuş olan veri giriş sayfasına girilerek, tek ağacın yaşlarda ya da yaş periyotlarındaki aldıkları çaplar $\mathrm{mm}$ cinsinden belirlenmiş olmaktadır. Böylece yaş ya da yaş periyodlarına göre düzenlenmiş olarak, ağacın hangi kesit yüksekliğinde kaç mm çapa ulaştığı belirlenmektedir (Şekil 2).
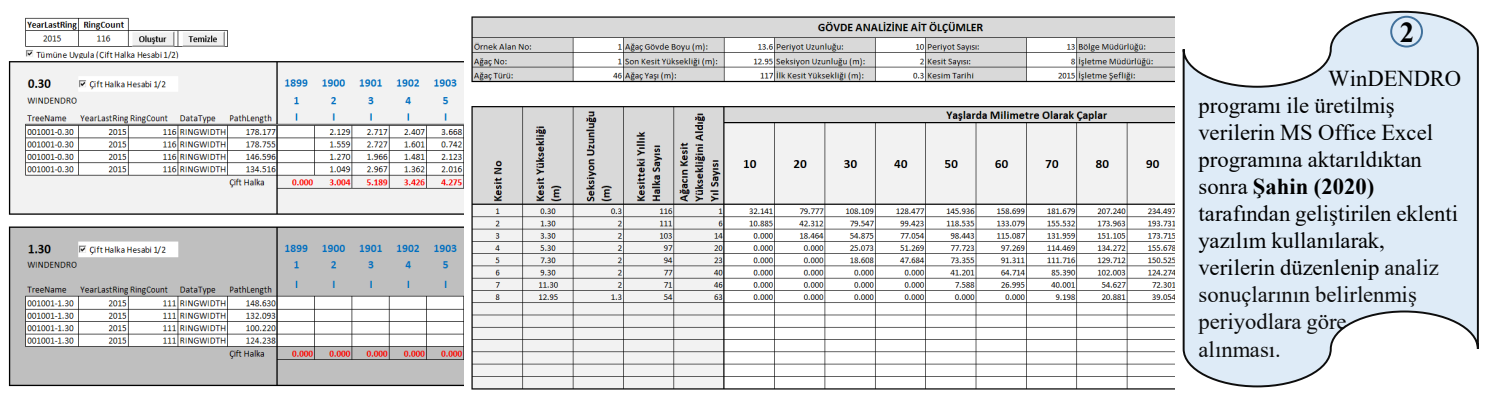

Şekil 2. Gövde analiz verilerinin düzenlenmesi

Üçüncü aşamada ise, ağacın hangi kesit yüksekliğinde kaç mm çapa ulaştığına ait veriler ile ağaca ait temel veri girișleri, Özdemir ve Özdemir (2016) tarafindan MS Excel 2010 programının VBA makro özelliğinden yararlanılarak tasarlanmış olan GOAP makro programına aktarılarak sonuçlar ve çıktılar bu programdan alınmaktadır. GOAP makro programında, yaş ya da periyodik yaşlara karşılik gelen gövde hacim değerlerinin bulunabilmesi için periyodik yaşlardaki ağaç boylarının tahmin edilmesi gerekmektedir. Bu amaçla, kesitteki yıllık halka sayıları ile ağaç yaşı arasındaki farklar hesaplanarak ağacın her bir kesit yüksekliğine ulaşma yaşları hesaplanmaktadır. Daha sonra kesit yüksekliği bağımlı, ağacın bu kesit yüksekliklerine ulaşmak için aldığı yıl sayısı bağımsız değişken alınarak boylanma modeli oluşturulmaktadır. GOAP makro programında yaş-boy ilişkisini ortaya koymak için Prodan modeli ile Quadratic (Polinom) denklem kullanılmakta ve sonuçlar her iki modele göre de üretilmektedir. GOAP makro programı kullanılarak, tek ağaca ilişkin kesitlerin yüzeyleri hesaplanmakta, ağacın dip, seksiyon ve uç hacmi ayrı ayrı hesaplanarak ağaç hacmi belirlenebilmektedir. Ağaç yaşı ya da yaş periyotlarına bağlı olarak, göğüs çapı, boyu ve hacmi ile bu parametrelerin artım değerleri de hesaplanmakta ve grafikleri elde edilebilmektedir (Şekil 3).

Sonuç olarak; kesitler ve artım kalemlerindeki yıllık halka genişliklerinin ölçülmesinde ve halka sayılarının belirlenmesinde, kesitlerin taranarak bilgisayara yüklenip ve sonrasında bilgisayar programları kullanılarak gövde analiz çalışmalarının yapılması, zaman açısından tasarruf sağladığı gibi kesit yüzeyi ya da artım kalemi üzerindeki her halkanın genişliğinin oldukça hassas bir şekilde belirlenmesini de sağlamaktadır. Örnek ağaçlara ait bilgilerin üretilmesi ve hesap işlerinin yapılması daha kolay, hızlı ve doğruluk derecesi daha yüksek bir şekilde gerçekleştirilmektedir. Tüm bu işlemler sonucunda örnek ağaçların hacim elemanları ve kabuksuz- 

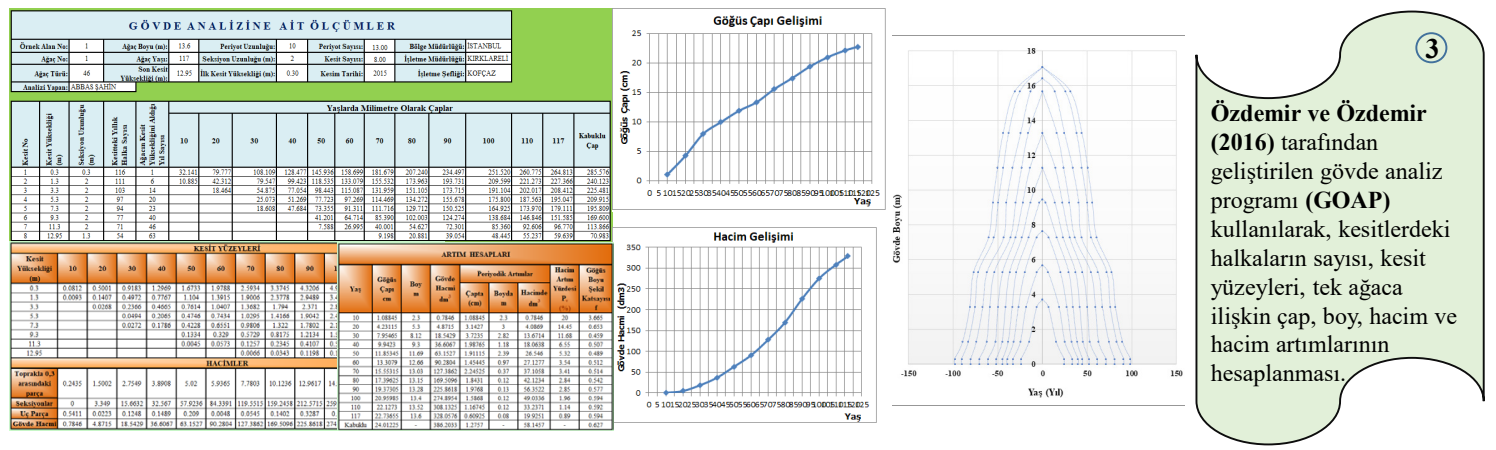

Şekil 3. Tek ağaca ilişkin bazı hasılat parametrelerinin GOAP makro programı ile hesaplanması

kabuklu gövde hacimleri oldukça yüksek doğruluk derecesiyle elde edilmektedir. Şahin (2020) ve Şahin ve ark. (2021) tarafindan gerçekleştirilen çalışmalarda yukarıda açıklanan yöntemler birebir uygulanmış ve oldukça verimli sonuçlar alınmıştır.

\section{Teșekkür}

WinDENDRO yazılımı ve tarayıcının araştırma çalışmalarımızda kullanılmasını temin eden Orman Genel Müdürlüğü Marmara Ormancılık Araştırma Enstitüsü Müdürlüğ̈̈’ne, Bilgisayar Mühendisi Fatih Alkan'a ise Şahin tarafından geliştirilen program eklentisine yaptığı katkıdan dolayı çok teşekkür ederiz.

\section{Kaynaklar}

Özdemir, G. A., Özdemir, E., 2016. Stem analysis prog- ram (GOAP) for evaluating of increment and growth data at individual tree. Journal of the Faculty of Forestry Istanbul University. İstanbul Üniversitesi Orman Fakültesi Dergisi, 66, 659-673.

Şahin, A., 2020, Marmara Bölgesindeki Sapsız Meșe (Quercus petraea (Mattuschka) Liebl.) Meşcerelerinin Hasılatı ve Amenajman Esasları. İÜ Fen Bilimleri Enstitüsü, Doktora Tezi, İstanbul.

Şahin, A., Özdemir, E., Aylak Özdemir, G., Biricik, Y., Korkmaz, Ü., Saraçoğlu, Ö. 2021. Macar Meşesi (Quercus frainetto Ten.) Meşcerelerinin Hasılatı (Proje No: 10.3201/2014-2018-2020). Marmara Ormancılık Araştırma Enstitüsü Müdürlügü, Araştırma Projesi Sonuç Raporu, 237 sayfa, İstanbul.

URL1: https://regentinstruments.com/assets/windendro_about.html (Son erişim tarihi:01.09.2021). WinDENDRO Tree-rings Analysis Programme. Canada 